\title{
Micropropagación de plátano enano (Musa spp) utilizando manos de flores masculinas inmaduras con diferentes concentraciones de desinfectantes y reguladores de crecimiento
}

\author{
Karla María Quintanilla Moreno
}

\author{
Licenciada en Biología Centro Nacional de Tecnología Agropecuaria y Forestal, CENTA \\ karla.quintanilla@centa.gob.sv
}

Recepción: 2014-04-23

Aceptación: 2014-05-23

\section{Resumen}

El plátano es un rubro alimenticio de gran importancia económica en el país, considerado como alimento de elevado consumo nacional. Uno de los fines fundamentales del cultivo in vitro -aplicado a la agricultura- es generar aumentos sustanciales en la producción y/o rendimiento de este rubro, a través de nuevos enfoques, permitiendo la expansión de la superficie sembrada. El objetivo principal de la investigación fue establecer un protocolo de micro propagación de plátano enano, usando manos de flores masculinas inmaduras con miras a la reducción de costos de producción in vitro.

La investigación inicialmente se llevaría a cabo en dos etapas, pero al final solo se realizó la etapa de establecimiento in vitro (desinfección superficial), debido a que se determinó que de la Musa spp. (Plátano variedad Enano), no es posible obtener plantas a través de inflorescencia masculinas. Esto se debió, en parte, a que los agentes desinfectantes no permitieron obtener explantes libres de contaminantes de patógenos; además de la acción de las polifenoxidasas, las cuales no expresaron la potencialidad de los explantes utilizados para el desarrollo de callos embriogénicos.

Palabras Clave: Micropropagación, plátano enano, flores masculinas inmaduras, fenolización, agente desinfectante.

\begin{abstract}
The plantain is a food industry that has a great economic importance in our country; it is considered as a national high consumed food. One of the fundamental purposes of the in vitro farming applied to agriculture - is to increase the production and / or the performance of this industry through the new approaches, allowing the expansion of the sown field. The main objective of this research was to establish a protocol of micro propagation of the Dwarf Cavendish Banana using handful immature male flowers with the purpose of reducing the in vitro production costs

Initially, this research was going to be carried out in two stages, but at the end it was done only the in vitro stage (superficial disinfection) because it was determined from Musa spp (Dwarf Cavendish banana) that it was not possible to get plants through the male inflorescence. This was because, somehow, that the disinfected agents did not allow to get explant free from pollutant pathogens; in addition to the action of the polyphenol oxidases, that did not show the potentiality of the explants used for the development of the embryogenic calli.
\end{abstract}

Key words: Micropropagation, dwarf Cavendish banana, immature male flowers, phenolization, disinfected agents. 


\section{Introducción}

El cultivo de musáceas es de gran importancia debido a su valor nutritivo. En ellas se destaca el contenido de carbohidratos (35\%), que en buena parte son transformados en glucosa, sacarosa y fructosa durante la maduración (6-7\% de fibra), (1-2\% de proteína, potasio, magnesio, fósforo, calcio, hierro y vitaminas A y C). Todos estos componentes logran cubrir las necesidades requeridas en la dieta básica de la población. Asimismo, su producción es de suma importancia económica para El Salvador, ya que gracias a ella se genera un aproximado de 24,790Tm anualmente (Arévalo, 2007). Todo esto la convierte en una especie que sumamente explotada por su valor comercial, que va en aumento a fin de representar una alternativa de dieta alimentaria.

La micropropagación o propagación clonal es una de las aplicaciones más generalizadas del cultivo in vitro, el cual se realiza a través de la micropropagación de un fragmento de una planta madre llamado explante. Con este procedimiento se obtiene una descendencia uniforme, es decir, plantas genéticamente idénticas, a las cuales se les denominada clones.

El explante más utilizado para los procesos de propagación in vitro son las yemas apicales vegetativas de las plantas (Castillo, 2004). Aunque diferentes explantes han sido utilizados para la propagación de plátano, en el proceso in vitro, el cultivo de meristemos apicales ha funcionado para muchas especies comerciales. Pero también la inflorescencia masculina presenta un potencial como explante regenerable para dicho fin (Kulkarni et al., 2004, 2006). Para ello se ha empleado la técnica de embriogénesis somática, donde la iniciación de los cultivos embriogénicos se realiza en diferentes partes de la planta como explantes: inflorescencias (flores masculinas y femeninas inmaduras), bases de las hojas jóvenes, fragmentos del rizoma (cormo) sin primordios meristemáticos, secciones de frutos, ápices florales y microcormos de plantas in vitro (Grapin et al., 1998; Schoofs et al., 1999; Trujillo y García, 1999).

El objetivo de este trabajo fue determinar la viabilidad de micropropagación de plátano enano, usando manos de flores masculinas inmaduras con miras a la reducción de costos de producción de plántulas in vitro. Esto no se estableció debido a que la inflorescencia inmadura masculina en este cultivar, no fue lo suficientemente perdurable, haciendo que los poco explantes obtenidos sufriera fenolización y se contaminaran, perdiendo su viabilidad para generar nuevas plántulas.

\section{Materiales y métodos}

El trabajo se efectuó en el área de cultivo de tejidos del laboratorio de biotecnología ubicados en las instalaciones de CENTA, El Salvador. Se dividió en dos etapas: la primera estuvo relacionada con el establecimiento in 
vitro, el cual permitiría la obtención de embriones viables para la fase de crecimiento; la segunda consistió en la regeneración de estos embriones en brotes.

Para la ejecución de la primera fase se utilizaron las manos de flores masculinas inmaduras, obtenidas de pichotas vigorosas provenientes de una parcela establecida, ubicada detrás de los invernaderos del laboratorio. Con ello se garantizó la pureza genética y fitosanitaria del material empleado.

\subsection{Etapa 1: Establecimiento in vitro}

Esta etapa incluyó la desinfección superficial del material considerado como explante. Para ello se utilizaron dos concentraciones $(\% \mathrm{~V} / \mathrm{V})$ de cloro comercial, evaluándose la solución de mayor efectividad.

Las flores inmaduras masculinas se obtuvieron de inflorescencias masculinas reducidas a $15 \mathrm{~cm}$. Luego, estas se redujeron a un tamaño inicial de $2.5 \mathrm{~cm}$ aproximadamente, a fin de efectuar el tratamiento de desinfección. Este se realizó a través de un lavado con jabón bactericida comercial durante $5 \mathrm{~min}$; seguido de un lavado con alcohol 70\% (v/v) durante un minuto. También se utilizó la concentración de cloro comercial a evaluar (Tratamientos), con la cual se lavó durante 10 minutos. Finalmente se procedió a aislar el explante con ayuda de un microscopio estereoscópico. Todo esto se llevó a cabo bajo condiciones asépticas (cámara de flujo laminar).
Al finalizar cada tratamiento de desinfección, las muestras cada una de las muestras se lavó tres veces con agua destilada estéril; y se mantuvieron en una solución antioxidante (cisteína: $60 \mathrm{mg} \cdot \mathrm{L}^{-1}+$ ácido ascórbico: 100 mg. $\left.\mathrm{L}^{-1}\right)$ hasta el momento de extracción de los explantes. Posteriormente, estas se cortaron longitudinalmente -a través del eje floral- en cuatro segmentos más o menos iguales. A su vez, cada segmento se dividió transversalmente en cinco secciones: cuatro secciones de aproximadamente $1 \mathrm{~mm}$ de ancho y una de $5 \mathrm{~mm}$ de ancho. Esta última corresponde a la parte más apical de la pichota (Figuras 1 y 2).

\section{Muestra del procedimiento de colecta de material}

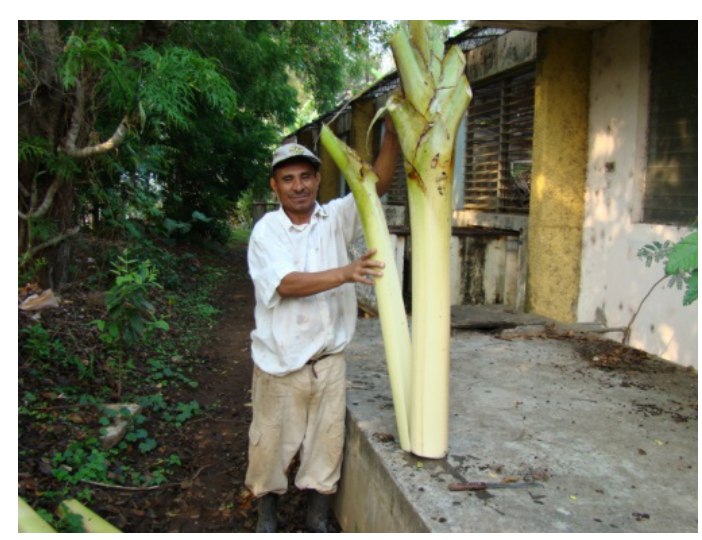

Figura 1. Muestra de Musa spp. Establecimiento in vitro (2013). 


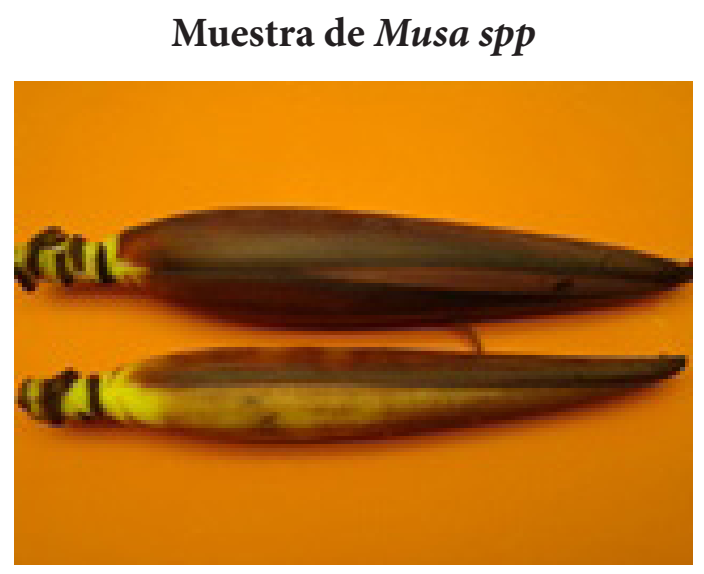

Figura 2. Material vegetal de Musa spp listo para utilizarse como explante. Establecimiento in vitro (2014).

\subsection{Variables estudiadas en la etapa 1}

Viabilidad. Se determinó mediante la inspección de los explantes que presentaron signos de necrosis, y aquellos que mostraron tejidos sanos. Se evaluó a cada uno de forma individual, durante cada semana a partir de su siembra, por un periodo de tres meses.

Tiempo de respuesta. Se revisó de forma diaria mediante una tabulación, a partir del día después de la siembra, en el que los explantes mostraron cambios significativos.

Contaminación. Se registraron a aquellos frascos que no presentaron contaminación (con un valor de 0 ), y los que se encontraron contaminados (con un valor de 1). Se evaluó cada una de las unidades experimentales a lo largo de cada semana, a partir de su siembra, por un período de tres meses.

\subsection{Descripción de tratamientos}

\begin{tabular}{|c|c|c|c|c|c|}
\hline $\begin{array}{l}\text { Número de } \\
\text { tratamiento }\end{array}$ & T1 & T2 & T3 & T4 & T5 \\
\hline Descripción & $\begin{array}{c}2.0 \% \\
\text { de cloro } \\
\text { comercial + } \\
2.0 \mathrm{mg} / \mathrm{l} \mathrm{de} \\
2,4-\mathrm{D}\end{array}$ & $\begin{array}{c}2.0 \% \\
\text { de cloro } \\
\text { comercial + } \\
4.0 \mathrm{mg} / \mathrm{l} \mathrm{de} \\
2,4-\mathrm{D}\end{array}$ & $\begin{array}{c}2.5 \% \\
\text { de cloro } \\
\text { comercial + } \\
2.0 \mathrm{mg} / \mathrm{l} \mathrm{de} \\
2,4-\mathrm{D}\end{array}$ & $\begin{array}{c}2.5 \% \\
\text { de cloro } \\
\text { comercial + } \\
4.0 \mathrm{mg} / \mathrm{l} \mathrm{de} \\
2,4-\mathrm{D}\end{array}$ & $\begin{array}{c}\text { Tratamiento } \\
\text { control }\end{array}$ \\
\hline
\end{tabular}

Diseño experimental: Se efectuó completamente al azar, en arreglo factorial 2x2 con seis observaciones por tratamiento.

Unidad experimental: Se colocó un explante dentro de una caja petri con su respectivo medio de cultivo.

Análisis estadístico: Es decir, el análisis de varianza.

\section{Análisis económico con presupuesto parcial}

Tiempo del estudio: 15 meses 


\section{Resultados y discusión}

Finalizada la etapa 1, durante la Micropropagación de plátano enano (Musa spp), utilizando manos de flores masculinas inmaduras, no se logró la obtención de embriones a regenerar dentro de la etapa 2; debido a que la pichota no perdura en su totalidad para la variedad enano (Figura 3). Por esta razón, los numerosos cortes que realizaron en los explantes para su iniciación in vitro, conllevaron oxidaciones fenólicas e inhibición en el crecimiento de los mismos, perdiéndose su viabilidad (Figura 4).

\section{Pasos del proceso de iniciación in vitro}

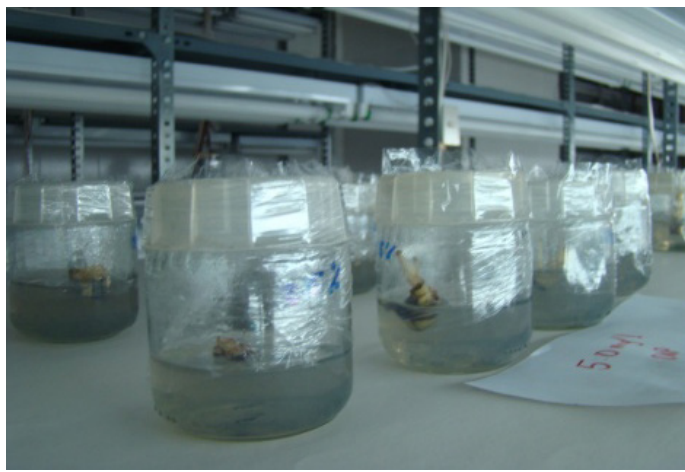

Figura 3. Explante inicial, Resultados y discusión. CENTA (2013).

Muestra de explante en iniciación in vitro

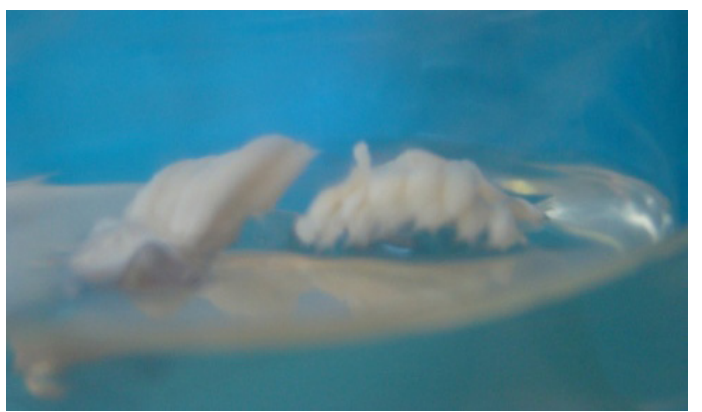

Figura 4. Vista panorámica de los explantes en cámara de crecimiento, Resultados y discusión. CENTA (2013).
Ante este fenómeno, se cultivaron los explantes en la oscuridad para reducir drásticamente su proceso de oxidación. Pero por tener una gran cantidad de compuestos fenólicos y de agentes desinfectantes, no se logró detener la perdida de estos explantes. Tal como lo mencionan Ramírez (1998); Anderson y Ievinsh (2002), la oxidación fenólica provoca un fenómeno de ennegrecimiento que ocurre por acción de enzimas tipo polifenoloxidasas y tirosinasas, las cuales se liberan o sintetizan cuando los tejidos sufren heridas muy parecidas a las realizadas por los cortes para extraer los explantes (Figura 5).

\section{Muestras de oxidación en explantes}

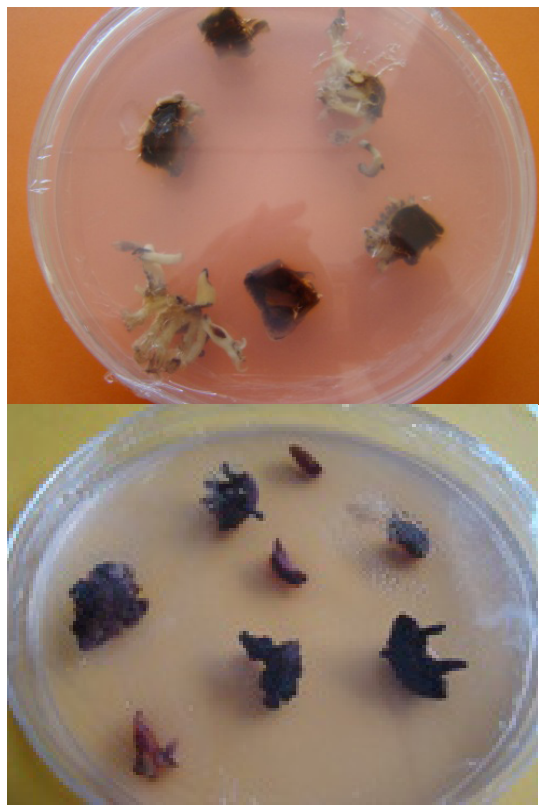

Figura 5. Oxidación fenólica de los explantes como resultado del proceso de desinfección superficial. CENTA (2013). 
El método de manos florales inmaduras masculinas es aplicable a la mayoría de los cultivares de Musa que producen flores masculinas (Strosse et al., 2006). Sin embargo, esta condición excluye a los nuevos clones que se encuentran en cantidades limitadas en el germoplasma de Musa. De estos últimos, se dispone de poco material vegetal en el campo.

En el caso particular del cultivo de tejidos in vitro, los procesos de oxidación son causados principalmente por el efecto abrasivo del agente desinfectante, aplicado durante la asepsia del explante; los cortes realizados, la composición del medio de cultivo, el volumen y la calidad del frasco de cultivo (George1993, Tabiyeh et al. 2006, Van Staden et al. 2006, Abdelwahd et al. 2008). Por todo esto, la célula sufre algún tipo de daño, estrés o se encuentra senescente $y$, generalmente, da como resultado la muerte del explante (Bhat y Chandel 1991, George, 1996, VatanpourAzghandiet al. 2002, Tang y Newton, 2004, Gratão et al. 2005, Pompeu et al. 2008).

La oxidación fenólica provoca un fenómeno de ennegrecimiento que ocurre por acción de enzimas tipo polifenoloxidasas y tirosinasas que se liberan o se sintetizan cuando los tejidos sufren heridas, iguales a las ocasionadas durante la realización de los cortes para extraer los explantes (Ramírez, 1998; Anderson y Ievinsh, 2002). Esto explica las oxidaciones fenólicas fuertes, debido a los numerosos cortes que deben realizarse en los explantes para su iniciación in vitro. Esto inhibe el crecimiento de los mismos y hace que se pierda su viabilidad.

En sus investigaciones, Escalant y Sandoval (1989) señalaron que la respuesta embriogénica depende del tipo de explante, destacando la utilidad de las inflorescencias masculinas como fuente de callos embriogénicos. Ese fenómeno concuerda con esta investigación dentro de la variedad enano, pues no se obtuvo mayor respuesta embriogénica por parte de los explantes, ya que la inflorescencia masculina solo permanece en algunos cultivares.

Con respecto al registro de contaminación, se logró establecer al menos un 40\% de los explantes (Figuras 6), ya que existió presencia de agentes contaminantes como hongos y bacterias propios del proceso de fenolización. Los explantes en los cuales sí se logró controlar la contaminación, se mantuvieron en el medio de cultivo por un tiempo aproximado de 6 meses, sin subcultivo en el cuarto de crecimiento, en espera de la formación de embriones (cambios morfogénicos). No obstante, la liberación de fenoles no se detuvo, perdiéndose siempre el explante. 
Muestras de contaminación bacteriana en explantes

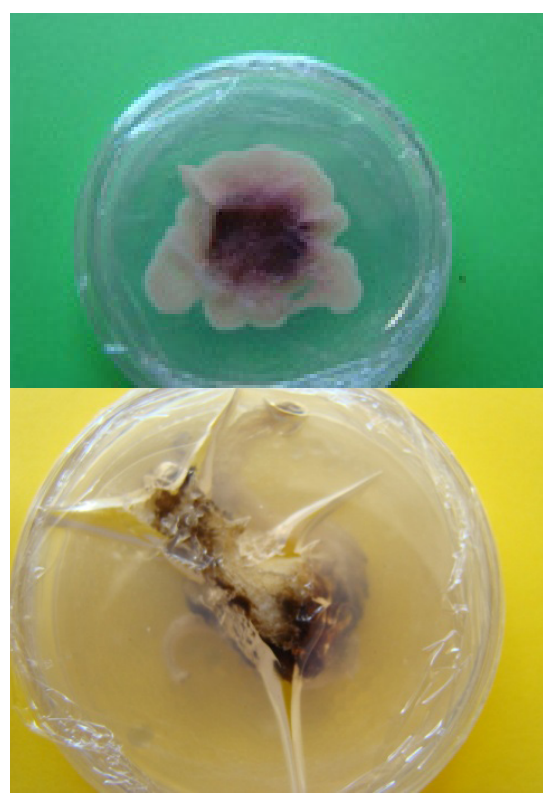

Figura 6. Contaminación bacteriana en manos de flores masculinas inmaduras de plátano enano. CENTA (2013).

Todos los explantes somáticos empiezan por producir glóbulos meristemáticos, también denominados callos nodulares. Estos glóbulos meristemáticos no son embriogénicos, pero pueden desarrollar estructuras embriogénicas o formar un callo blanco traslúcido, en donde se forman después de un tiempo de cultivo prolongado (Escalant et al., 1994). Sin embargo, la misma contaminación endógena del material no logró controlarse, al mismo tiempo que el proceso de fenolización hizo perder los explantes aun viables.

El grado de oxidación fue en aumento, al grado de generarse la liberación de exudados, los cuales terminaron por causar un daño mayor a los explantes. Este dato es un punto de partida muy importante para buscar explantes que se formen a partir de una o pocas células como los embriones somáticos (Lee et al., 1997); y yemas adventicias (Vuylsteke et al., 1997). No obstante, ello dependerá de la variedad de musa a investigar, ya que en el guineo del tipo "majoncho", la yema floral perdura, a tal grado de permitir extraer explantes de forma viable mediante esta técnica (Figuras 9 y 10).

\section{Muestra de yemas de guineo majoncho}

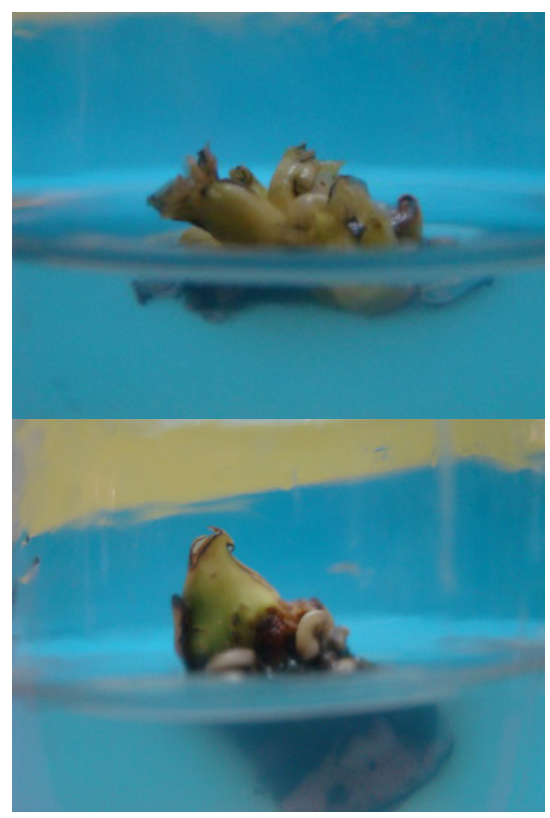

Figura 7. Yemas provenientes de inflorescencia masculina de guineo majoncho. CENTA (2013).

A partir de flores masculinas se han propagado plantas por embriogénesis somática en guineo Enano (Escalant etal., 1994), así como otros tipos de bananos. No obstante, el porcentaje de yemas masculinas que forman 
callos embriogénicos depende del genotipo (Grapin etal., 1998). Cuando no es posible obtener flores masculinas, como en el caso de los plátanos, el cultivo de ápices caulinares es una opción para inducir la embriogénesis somática (Schoofs, 1999) o el cultivo de flores femeninas. Por ello se sugiere profundizar en esta metodología.

\section{Conclusiones}

La Micropropagación de plátano enano (Musa spp) utilizando manos de flores masculinas inmaduras con diferentes concentraciones de desinfectantes y reguladores de crecimiento no es viable. Se comprobó que la utilización de diferentes concentraciones de agentes desinfectantes no permitió la obtención de explantes libres de contaminantes patógenos. Además, por la acción de las poli- fenoxidasas, la potencialidad de los explantes utilizados para la micropropagación de plátano enano no fue viable.

Por otra parte, no se evidenció acción morfológica y fisiológica como resultado de la utilización de diferentes concentraciones de crecimiento, para obtener callos embriogénicos en plátano enano.

Este resultado plantea la necesidad de evaluar la Micropropagación de plátano enano (Musa $s p p$ ) utilizando manos de flores femeninas inmaduras con diferentes concentraciones de desinfectantes y reguladores de crecimiento. Asimismo, se contempla la utilización de esta misma metodología, probando diferentes variedades de Musa para determinar los tipos de variedad en las cuasles resulta viable. Esto con miras a la reducción de costos de producción de plántulas in vitro.

\section{Referencias}

Anderson, U. y Ievinsh, G. (2002). Changes of morphogenic competence in mature Pinus sylvestris L. buds In vitro. Annals of Botany 90(2):293-298

Arévalo, C. (2007). El cultivo del plátano. Laboratorio de Biotecnología, CENTA-MAG. Boletín informativo.8pp

Castillo, A. (2004). Propagación de plantas por cultivo in vitro: una biotecnología que nos acompaña hace mucho tiempo. Recuperado de http://www.inia.org.uy/publicaciones/documentos/ lb/ad/2004/ad_382.pdf

Escalant, J. y Teisson, C. (1989). Somatic embryogenesis and plants from immature zygotic embryos of the species Musa acuminata and Musa balbisiana. Plant Cell Rep.7:665-668 
Escalant, J.V., Teisson, C. y Cote, F. (1994). Amplified somatic embryogenesis from male flowers of triploid banana and plantain cultivars (Musa spp.). In vitro Plant Cell. and Dev Biol. 30, 181-186

Grapin, A. y otros (1998). Obtención de callos embriogénicos, iniciación y regeneración de suspensiones celulares embriogénicas a partir de flores inmaduras masculinas y femeninas de Musa. InfoMusa 7(1): 13 - 15. Recuperado de http://www.vinculando.org/.../mejoramiento_ genetico_aplicadas_musaceas.mx

Kulkarni, V. M. y otros (2004). Differential effect of genome and cytokinins on shoot-tip cultures of Indian banana cultivars. Physiol. Mol. Biol. Plant 10: 75-81.

Kulkarni, V. M. y otros (2006). Plant regeneration through multiple shoot formation and somatic embryogenesis in a commercially important and endangered Indian banana cv. Rajeli. Curr. Sci. 90: 842-846.

Ramírez, M. (1998). Tratamientos a plantas madres y al explante para el establecimiento in vitro del guayabo (Psidium guajava L.). Trabajo de Grado. Maracaibo,Ven. La Universidad del Zulia. Facultad de Agronomía. División de Estudios para Graduados. Programa Fruticultura. Venezuela. $132 \mathrm{p}$.

Schoofs, H. y otros (1999). Cuellos de botella en la generación y mantenimiento de las suspensiones celulares morfogénicas de banano y la regeneración de las plantas vía embriogénesis somática a partir de ellas. InfoMusa 8(2): 3 - 7. Recuperado de http://www.vinculando.org/.../ mejoramiento_genetico_aplicadas_musaceas.mx

Strosse, H. y otros (2006). Development of embryogenic cell suspensions from shoot meristematic tissue in bananas and plantains (Musa spp.). Plant Science 170: 104-112

Trujillo, I., de García, E. y Berroteran, J. (1999). Evaluación de plantas de banana obtenidas in vitro. Anales de Botánica Agrícola 6: 29 - 35. Recuperado de htpp://www.vinculando.org/.../ mejoramiento_genetico_aplicadas_musaceas.mx 